\title{
Nuclear Pore Complexes Guardians of the Nuclear Genome
}

\author{
M. CAPelson, C. Doucet, AND M.W. Hetzer \\ Salk Institute for Biological Studies, Molecular and Cell Biology Laboratory, La Jolla, California 92037 \\ Correspondence: hetzer@salk.edu
}

\begin{abstract}
Eukaryotic cell function depends on the physical separation of nucleoplasmic and cytoplasmic components by the nuclear envelope (NE). Molecular communication between the two compartments involves active, signal-mediated trafficking, a function that is exclusively performed by nuclear pore complexes (NPCs). The individual NPC components and the mechanisms that are involved in nuclear trafficking are well documented and have become textbook knowledge. However, in addition to their roles as nuclear gatekeepers, NPC components - nucleoporins - have been shown to have critical roles in chromatin organization and gene regulation. These findings have sparked new enthusiasm to study the roles of this multiprotein complex in nuclear organization and explore novel functions that in some cases appear to go beyond a role in transport. Here, we discuss our present view of NPC biogenesis, which is tightly linked to proper cell cycle progression and cell differentiation. In addition, we summarize new data suggesting that NPCs represent dynamic hubs for the integration of gene regulation and nuclear transport processes.
\end{abstract}

The nuclear envelope (NE) is perforated by nuclear pore complexes (NPCs), which are large multiprotein channels mediating macromolecular import and export by an active, signal-dependent process (Kohler and Hurt 2007; Terry et al. 2007). Unlike other cellular transport channels, NPCs span a double lipid bilayer constituted by the outer nuclear membrane (ONM) and the inner nuclear membrane (INM), which are fused at sites of NPC insertion. The highly curved pore membrane is energetically unstable, and thus nuclear pores have an important structural role in maintaining the integrity of the transport channels. Each nuclear pore has a diameter of $\sim 50 \mathrm{~nm}$, exhibits a total molecular mass of $\sim 60 \mathrm{MDa}$, and is thought to contain more than 500 polypeptides (Hinshaw et al. 1992; Stoffler et al. 2003; Beck et al. 2004; Alber et al. 2007). This large number of NPC components is the result of the assembly of multiple copies of $\sim 30$ different nucleoporins (NUPs), which give rise to an eightfold symmetrical protein complex (Strambio-De-Castillia et al. 2010). The NPC is organized in a protein scaffold, which is anchored in the NE by at least three transmembrane NUPs. Eight filaments extend from this core structure into the cytoplasm and the nucleoplasm, the latter being frequently referred to as the "nuclear basket" (Fig. 1). In addition, the central core is coated by natively unfolded NUPs containing up to 50 repeat motifs that are rich in phenylalanine and glycine residues (FG repeats) (Alber et al. 2007; Terry and Wente 2009). These largely hydrophobic patches constitute the central channel of the pore and transiently bind to nuclear transport receptors during translocation of cargo molecules across the NPC. At the same time, NPCs establish an efficient permeability barrier for macromolecules larger than $30-40 \mathrm{kDa}$ and thus prevent the uncontrolled mixing of nucleoplasmic and cytoplasmic components (Weis 2003). Because the role of NUPs in nuclear trafficking and the various models of the physical properties of the permeability barrier have been discussed in many excellent reviews (Terry et al. 2007; Lim et al. 2008; Terry and Wente 2009; Strambio-De-Castillia et al. 2010; Walde and Kehlenbach 2010; Wozniak et al. 2010), we focus on the biogenesis of the NPC and discuss its role in chromatin organization and gene regulation.

\section{THE BIOGENESIS OF THE NUCLEAR PORE}

Considerable progress has been made in deciphering the molecular mechanisms involved in NPC biogenesis. Immunodepletion of NUPs from Xenopus egg extracts, small interfering RNA (siRNA)-mediated knockdown in cultured cells, or knockout strategies in yeast and animals have led to the identification of individual NUPs or subcomplexes involved in the NPC assembly process. The one NPC substructure that was consistently identified across different experimental strategies as being essential for NPC formation is the Nup107/160 subcomplex (Siniossoglou et al. 1996; Boehmer et al. 2003; Harel et al. 2003b; Walther et al. 2003a). The transmembrane NUPs POM121 and Ndc1 in vertebrates have also been shown to decrease pore density, in a partially redundant manner (Mansfeld et al. 2006; Stavru et al. 2006a,b). Accordingly, the yeast transmembrane NUPs Pom34, Pom152, and Ndc1 have been shown to be involved in NPC assembly, Ndc1 being essential, whereas Pom34 and Pom152 have partially redundant functions (Madrid et al. 2006; Miao et al. 2006). It thus appears that most core NUPs are essential for NPC assembly or maintenance.

Studying the mechanisms of NPC formation at the molecular level is complicated by the fact that in metazoa, nuclear pores assemble at different cell cycle stages. At the end of mitosis, when the NE reforms around segregated chromosomes, NPCs reform from disassembled precursors (Antonin et al. 2008). In addition, new NPCs 

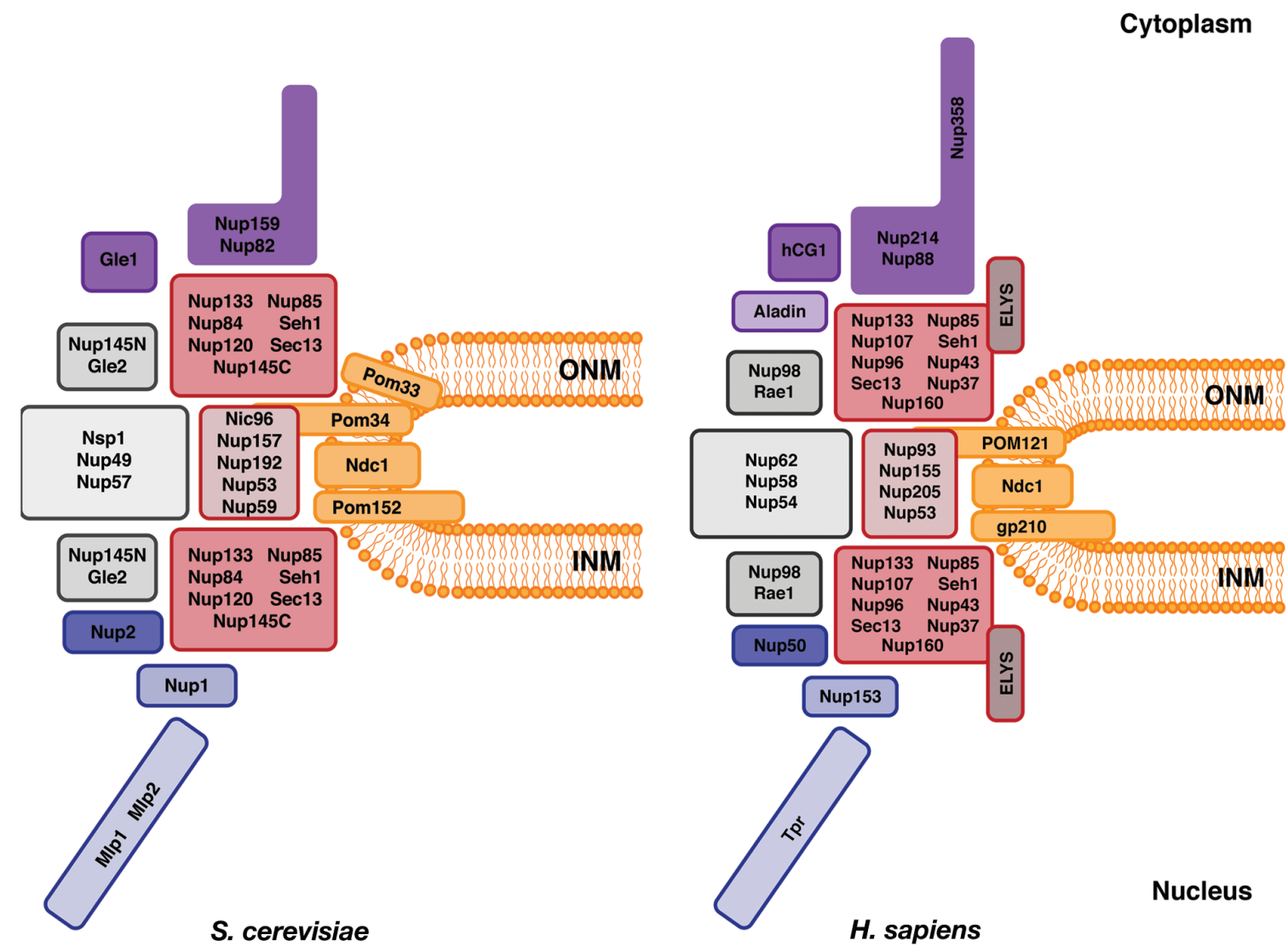

Figure 1. Composition of yeast (left) and mammalian (right) NPCs. Framed boxes represent individual NUPs or subcomplexes. (Orange) Transmembrane NUPs, (red) soluble scaffold components, (gray) central core NUPs, (violet) components of the cytoplasmic filaments; (dark and light purple) members of the nuclear basket. Note that the relative position of the components is not meant to represent the structure of the NPC beyond this general organization.

continuously assemble in interphase into the expanding NE (Maul et al. 1971). This "interphase" NPC assembly, thought to provide a sufficient number of NPC components for daughter cells during the next cell division, occurs in an intact NE. Importantly, organisms with closed mitosis, such as budding and fission yeast, only assemble NPCs into an intact NE (Winey et al. 1997), suggesting that the postmitotic NPC assembly pathway evolved from the "interphase" mechanism with the advent of open mitosis. It is important to note that the assembly of NPCs into an existing $\mathrm{NE}$ is not restricted to dividing cells but also occurs during cell differentiation. For instance, millions of NPCs are assembled during oogenesis, and cells undergoing endoreplication continue assembling NPCs during differentiation (Burke and Ellenberg 2002). Moreover, "interphase" assembly occurs in response to changes in metabolic activities, as in lymphocytes, where NPC density nearly doubles following stimulation with phytohemagglutinin in the absence of cell division (Maul et al. 1971). Very little is known about potential differences between postmitotic and interphase NPC assembly, which can be explained at least in part by the wide use of an in vitro NPC assembly assay based on cell-free Xenopus egg extracts. This experimental system recapitulates the postmitotic assembly of the NE and NPCs (Dabauvalle and Scheer 1991; Forbes 1992). Moreover, because asynchronous cultured metazoan cells and whole organisms convey both postmitotic and interphase NPC assembly, most studies performed in these systems did not distinguish between the two pathways. In the past years, single-cell live imaging provided cell-cycle-specific information about NPC assembly (Bodoor et al. 1999; Hase and Cordes 2003; D'Angelo et al. 2006; Dultz et al. 2008; Doucet et al. 2010). Moreover, the Xenopus egg extract system can be adapted to distinguish between postmitotic NPC assembly (occurring during the early time points of the nuclear assembly reaction) and interphase assembly, which occurs later during the nuclear expansion phase (D'Angelo et al. 2006; Dawson et al. 2009; Doucet et al. 2010). Different experimental strategies using this system can also lead to the formation of pore-free NEs, in which the mechanisms of pore formation in an intact NE can be studied in vitro (Harel et al. 2003b; Fichtman et al. 2010).

\section{Postmitotic NPC Assembly}

In metazoa, postmitotic NPC assembly is concomitant with NE reformation and involves the ordered recruitment of ER membranes and disassembled NPC components to chromatin (Anderson and Hetzer 2008b). Nucleoporins have open access to chromatin, and transmembrane NUPs can freely diffuse between both sides of the reforming nuclear membranes. Chromatin constitutes a matrix for NPC formation, and recruitment of NUPs to chromatin has been 
shown to occur independently of membranes. For instance, the Nup107/160 complex is targeted to chromatin via ELYS/Mel-28, which directly binds to DNA through an AT-hook (Rasala et al. 2006, 2008; Franz et al. 2007). This step is controlled by a cross talk between the small GTPase Ran and the transport receptor importin $\beta$ (Harel et al. 2003a; Walther et al. 2003b; Rotem et al. 2009). Association of importin $\beta$ to the Nup107/160 complex prevents its targeting to chromatin as well as further association with other NPC members. Interaction of RanGTP with importin $\beta$ releases the Nup107/160-ELYS complex and promotes its subsequent chromatin binding (Fig. 2).

A second step in NPC formation involves the recruitment of transmembrane NUPs to chromatin. In vitro, the recruitment of membrane vesicles containing Pom121 and Ndc1, but not gp210, was shown to depend on previous Nup107/ 160 recruitment (Rasala et al. 2008). Accordingly, an interaction between the cytoplasmic domain of Pom121 and the Nup107/160 complex was characterized (Rasala et al. 2008). It is now clear that membrane vesicles most likely result from fractionation of the endoplasmic reticulum (ER) occurring during preparation of cell-free extracts and that postmitotic NE formation actually results from reshaping of the ER around chromatin (Anderson and Hetzer 2007). INM proteins as well as the transmembrane NUPs Pom121 and Ndc1 were shown to mediate this process, by driving the spreading of the mitotic ER on segregated chromatin through their capacity to bind DNA in a collaborative manner (Anderson et al. 2009). In the particular case of Pom121, this is likely mediated by its interaction with the chromatinbound Nup107/160 complex. Indeed, a systematic analysis of the kinetics of NUPs recruitment to the reforming NE revealed that Pom121 was targeted to chromatin after the Nup107/160 complex (Dultz et al. 2008). Moreover, the Pom121-Nup107/160 interaction may be important to initiate the connection between soluble members of the NPC and the reforming NE (Antonin et al. 2005). However, it was recently shown in vivo and in vitro that Pom121 is not rate limiting for NPC assembly at the end of mitosis (Doucet et al. 2010); this observation may account for the previously suggested overlapping functions of $\mathrm{Ndc1}$ and Pom121 in NPC assembly (Stavru et al. 2006a). Notably, the third transmembrane NUP gp210 is recruited later to the chromatin periphery (Bodoor et al. 1999), suggesting that it is not involved in the early membrane association of the reforming pore. Electron microscope (EM) analysis of nuclear assembly reactions in Xenopus egg extracts revealed that membrane-free chromatin is coated with single copies of ELYSbound Nup107/160 complexes, suggesting that the lateral oligomerization of the complex is promoted by the interaction with membranes and/or Pom121 (Rotem et al. 2009).

A third step in NPC formation includes the recruitment of Nup93, Nup98, and the Nup62 complex (Bodoor et al. 1999; Dultz et al. 2008). Nup93 is in complex with other members including Nup53 and Nup155. Interestingly, Nup53 interacts with Ndc1 (Hawryluk-Gara et al. 2005; Mansfeld et al. 2006), and Nup155 was shown to be critical for NE formation in Xenopus extracts and in Caenorhab-

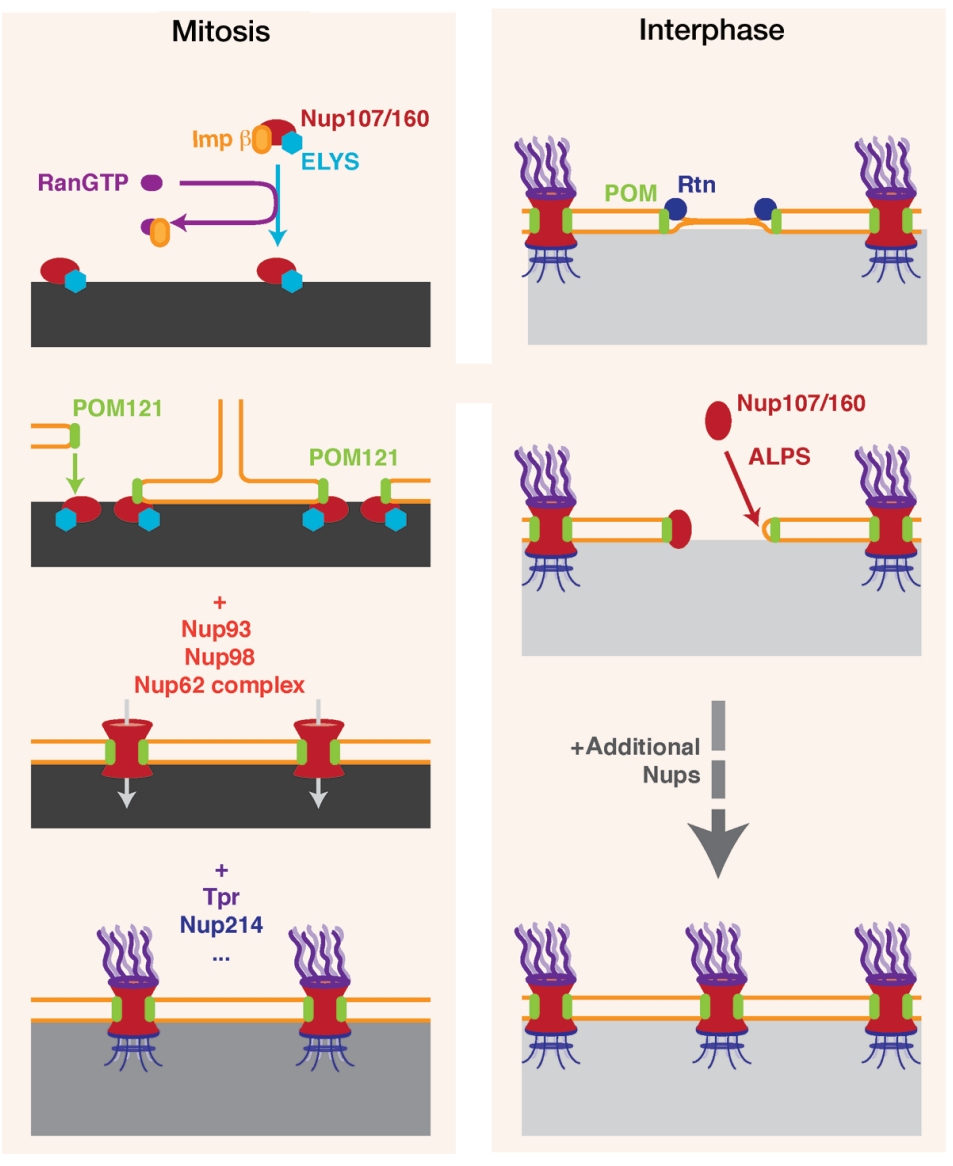

Figure 2. Model for mammalian NPC assembly mechanisms in mitosis and interphase. (Top to bottom) Sequences of events leading to postmitotic (left) or interphase (right) NPC assembly. (Gray) Chromatin; the intensity of the color reflects its compaction state. 
ditis elegans embryos (Franz et al. 2005). This suggests that the recruitment of the Nup93 complex at this stage may be critical to stabilize the interaction between the NPC and the NE. Because Nup93 and Nup98 briefly precede Nup58 (a member of the Nup62 complex) on chromatin, they might be involved in recruiting the Nup62 complex (Dultz et al. 2008), which is consistent with previous data showing that Nup98 depletion in mice leads to a defect in Nup62 assembly (Wu et al. 2001). Importantly, the association of these components was shown to coincide with the activation of nuclear import (Dultz et al. 2008). The Nup62 complex and Nup98 contain FG repeats, which are known to interact with transport receptors (Terry and Wente 2009) and are sufficient to recapitulate selective nuclear transport (Frey and Gorlich 2007; Jovanovic-Talisman et al. 2009). Moreover, the Nup93 complex significantly contributes to the establishment of the size exclusion limit of the NPC (Shulga et al. 2000; Galy et al. 2003).

The last step of postmitotic NPC assembly is the recruitment of peripheral NUPs, including Nup214, Tpr, and the major pools of Nup50 and Nup153 (Bodoor et al. 1999; Haraguchi et al. 2000; Hase and Cordes 2003; Dultz et al. 2008; Katsani et al. 2008). This is consistent with studies showing that gp210 and Nup214 are dispensable for the assembly of the NPC core (Walther et al. 2001; Galy et al. 2008). Although the scaffold core of the NPC has a twofold symmetry about the NE plane, a number of peripheral NUPs are asymmetrically localized (e.g., components of the nuclear basket and cytoplasmic filaments) (see Fig. 1). How the observed asymmetry is established and maintained remains to be determined.

\section{Interphase NPC Assembly}

In interphase, the topology of the NE, and thus the context of NPC assembly, differs from the situation at the end of mitosis, i.e., the NE is intact and therefore the nucleoplasm and cytoplasm are physically separated. Using Xenopus egg extracts, it was shown that in intact nuclei, the Nup107/160 complex was required from the nuclear and cytoplasmic sides of the NE to support new pore assembly (D'Angelo et al. 2006). This study implies that at least a fraction of the Nup107/160 complex was assembled in new pores without interacting with chromatin. This idea is further supported by the finding that ELYS is not rate limiting for interphase NPC assembly. Notably, no homolog of Elys has been identified in yeast, which undergoes closed mitosis, but an ortholog of Elys was discovered in Aspergillus nidulans, a fungus undergoing partial NPC disassembly during mitosis (Liu et al. 2009). However, this protein is shorter than vertebrate Elys and lacks an AT-hook. Instead, An-Elys is involved in the maintenance of the An-Nup84 complex in the NE during mitosis, suggesting that Elys is not restricted to vertebrates but may have been an early determinant in the evolution of organisms toward open mitosis.

Then, how is the Nup107/160 complex targeted to new NPC assembly sites? At least part of the answer can be found in a membrane-curvature sensor domain that is present in Nup133, a member of the Nup107/160 complex.
This so-called ALPS domain is an amphipathic $\alpha$-helix harboring a hydrophobic patch and an uncharged polar face (Drin et al. 2007). As opposed to classical amphipathic helices, interacting with lipid bilayers through hydrophobic and electrostatic interactions, interaction of these uncharged helices with membranes requires accessibility to the carbon tails of the lipids because they mainly bind through hydrophobic interactions. As a result, ALPS motifs preferentially associate with lipid bilayers exhibiting a loose lipid packing, which is typically achieved in curved membranes (Antonny 2006). The ALPS motif of Nup133 was shown to be specifically required for Nup107/160 recruitment to the NE and NPC assembly in interphase (Doucet et al. 2010). It is not clear yet if the ALPS domain participates in the fusion of INM and ONM by stabilizing the highly curved pore membrane. In vitro data suggest that this motif does not have affinity toward membrane sheets (Drin et al. 2007; Doucet et al. 2010) and therefore is unlikely to mediate fusion. The ability to directly sense the highly curved sites of ONM and INM fusion (or intermediates) ensures high specificity regarding the sequence of events and spatial restriction of pore assembly. It also provides an elegant mechanism for Nup107/160 targeting from both sides of the NE to new assembly sites. Interestingly, the ALPS domain of Nup133 is dispensable for postmitotic assembly, suggesting that the initial connections between soluble NUPs and the nuclear membrane are mediated by different mechanisms.

Once targeted to new sites, the Nup107/160 complex is incorporated into the NE to establish the NPC scaffold structure. A critical step in this process is mediated by the RanGTPase and the transport receptors importin $\beta$ and transportin (Lusk et al. 2002; Ryan et al. 2003; D'Angelo et al. 2006). RanGTP interacts with transport receptors sequestering Nup107/160 members and releases them to allow protein-protein interactions among complexes. Importantly, the generation of RanGTP is also required from both sides of the NE (D'Angelo et al. 2006).

Interestingly, although Pom 121 is recruited to new pore sites after the Nup107/160 complex during postmitotic NPC assembly, its recruitment precedes that of the Nup107/ 160 complex in intact NEs (Doucet et al. 2010). Indeed, pore intermediates harboring Pom121, but not Nup107 or Nup133, were characterized. Moreover, Pom121 knockdown inhibited Nup107 recruitment to the NE, and mistargeting the Nup107/160 complex increased the number of intermediates containing only Pom121 (Doucet et al. 2010). Finally, Pom 121 contains a functional NLS that is specifically required for interphase assembly, suggesting that the transmembrane NUP is delivered to the INM by an active transport process or that interactions of Pom 121 with other NUPs are regulated by importin $\alpha$ (Doucet et al. 2010; Yavuz et al. 2010).

It is not clear yet how and when the other NPC components are recruited and assembled into new pores during interphase and how the permeability barrier is preserved while new pores are inserted into the intact NE. It is striking that interphase pore insertion is a long process $(\sim 30$ $60 \mathrm{~min}$ ) compared to postmitotic assembly, which occurs in a few minutes (D'Angelo et al. 2006; Dultz and Ellen- 
berg 2010). One possibility is that narrow channels are initially formed and gradually expand as more components are assembled into the NPC. It is also possible that fusion intermediates are sufficient to allow the recruitment of the Nup107/160 complex as well as other NUPs and that completion of membrane fusion is ultimately coupled to assembly of FG-rich NUPs. More work is needed to clarify these mechanisms.

\section{Fusion of Inner and Outer Nuclear Membranes}

NPC formation in an intact NE occurs by a de novo process (D'Angelo et al. 2006), which implies that NPC formation involves fusion of the INM and ONM. Scanning EM studies have provided some potential intermediates including inward dimpling of the nuclear membranes and fusion of the bilayers (Goldberg et al. 1997). Although further investigations are required to test if these NE structures represent INM-ONM fusion intermediates, they highlight the fact that INM and ONM fusion must involve intermediates harboring a complex topology of positive and negative curvature to allow the close apposition of the membranes required for fusion. Curved lipid bilayers exhibit a differential packing of their two leaflets, which can be induced by a change in lipid composition (e.g., introduction of conical lipids) or by membrane-bending proteins (Antonny 2006). Transmembrane NUPs have long been suspected to have a critical role in NPC assembly and possibly INM and ONM fusion. In particular, the NUP gp210, which contains a large luminal domain that could in principle span the perinuclear space and bridge the ONM and INM, was suspected to be the key fusogenic component. However, the fact that gp210 is not expressed in many cell types argues against a general role of this NUP in membrane fusion (Olsson et al. 1999). Instead, recent evidence in human cells suggests that Pom121 might be involved in membrane fusion (Fichtman et al. 2010). As mentioned above, depletion of Pom 121 by RNAi specifically inhibited interphase pore assembly in cultured mammalian cells, and a Pom121-specific inhibitory antibody prevented ONM and INM fusion in vitro in expanding nuclei (Doucet et al. 2010). Pom121 might thus induce or stabilize membrane fusion. Its luminal domain is only $\sim 30$ amino acids in length and therefore likely cannot span the perinuclear space of the NE. It remains to be tested whether Pom121 recruits luminal ER proteins to induce INM and ONM fusion. Alternatively, Pom121 might cooperate with reticulons (Rtns), which have also been implicated in NPC assembly (Dawson et al. 2009).

The Rtns, structurally related to Yop1 and metazoan DP1, are thought to trigger or stabilize membrane curvature by inserting a wedge-like hydrophobic hairpin within one leaflet of a lipid bilayer (Sheetz et al. 1976; Oertle and Schwab 2003; De Craene et al. 2006; Voeltz et al. 2006; Shibata et al. 2008). Interestingly, Rtns have been implicated in NPC formation in an intact NE (Dawson et al. 2009), suggesting that they might induce the NE bending required for INM and ONM fusion. Indeed, codepletion of Rtn1 and Yop1 in yeast leads to NPC assembly phenotypes indicative of membrane fusion defects. Moreover, an in- hibitory antibody directed against Rtn4 (Voeltz et al. 2006) prevents INM and ONM fusion in Xenopus egg extracts (Dawson et al. 2009). Because flat membranes, and in particular the NE, are mostly devoid of Rtns, that reside preferentially in the tubular ER (De Craene et al. 2006; Voeltz et al. 2006; Anderson and Hetzer 2008a), the mechanisms by which they may trigger nuclear membrane bending are not clear. An appealing model is that Rtns would adopt a transient ring-like organization in the NE and displace the lipids on the outer leaflet of the ONM, from the site of their insertion toward the center of the ring. The lipid displacement would induce a combination of positive and negative curvature and result in the ONM getting closer to the INM. Because NPCs exhibit an eightfold radial symmetry, the ring-like organization of Rtns might result from their interaction with transmembrane NUPs. Coincidently, a novel transmembrane NUP, Pom33, was recently identified in yeast and shown to interact with Rtn1 (Chadrin et al. 2010). Rtns are likely rapidly replaced by components able to stabilize the curved pore membrane. Interestingly, multiple soluble NUPs have putative membrane interaction domains (specifically vNup133, yNup170, and yNup53) (Marelli et al. 2001; Drin et al. 2007; Patel and Rexach 2008). In particular, the ALPS motif of Nup133 may replace Rtns in the outer leaflet of bent nuclear membranes through its membrane-curvature-sensing ability and stabilize the fusion sites/intermediates.

Once membrane fusion has occurred, additional interactions are likely required to stabilize the highly curved pore. Strikingly, several components of the yNup84/vNup107-160 complex exhibit structural similarities with proteins of the COPII complex, suggesting that they may oligomerize in a similar structure to form a membrane coat and stabilize the pore membrane (Debler et al. 2008; Brohawn and Schwartz 2009; Whittle and Schwartz 2009). In addition, in yeast, the transmembrane NUPs physically interact with yNup170/ yNup157 and yNup53/yNup59 proteins (Flemming et al. 2009; Makio et al. 2009; Onischenko et al. 2009). In addition, genetic interactions between this network of NUPs and Rtn1/Yop1 further support the linkage among the transmembrane NUPs, Rtns, yNup170/yNup157, and yNup53/yNup59 steps (Dawson et al. 2009). As mentioned above, vNdc1 also functionally interacts with Nup53, an ortholog of yNup53/ yNup59, suggesting that the functional interactions characterized in yeast may be conserved in vertebrates (Mansfeld et al. 2006). Although a potential role of $\mathrm{Ndcl}$ in membrane fusion is not known, this transmembrane NUP may be crucial for the stabilization of the pore membrane through its interaction network with the soluble core of the NPC.

\section{ROLE OF THE NPC IN REGULATION OF GENE EXPRESSION}

Eukaryotic gene expression is regulated at multiple levels in the cell nucleus, from chromatin modification and compaction to the synthesis, processing, and export of mRNA. The precise execution of transcriptional programs during development and in dividing differentiated cells relies on faithful reproduction of a specific gene-expression state through mitosis and is crucial for maintaining correct 
cellular identity. Nucleocytoplasmic transport, which occurs exclusively through the NPC, controls the access of chromatin-modifying enzymes and transcription factors and the exit of RNA and, as such, is intimately tied to regulation of eukaryotic gene expression. Yet, in addition to the more established roles of NUPs in the transport process, it is becoming evident that the NPC components have additional functions in gene regulation and in nuclear organization of chromatin (Akhtar and Gasser 2007; Brown and Silver 2007). Recent evidence suggests that NUPs are able to interact physically with specific genomic loci and, via such direct interaction, can regulate transcriptional status of its targets and participate in chromatin domain establishment. These uncovered additional functions of NUPs suggest that they may have a critical role in setting up or maintaining transcriptional identity of developing and differentiated cells in a chromatin-associated manner. The major unresolved questions arising from these studies are the molecular nature and the cellular purpose of the NUP-gene contacts.

Interestingly, the proposed role of NUPs in developmental gene regulation is supported by reports of several NPC components exhibiting tissue-specific expression and tissue-specific disease phenotypes (Capelson and Hetzer 2009). Given the indispensable role of the NPC in cellular function, tissue-specific requirements of NUPs can appear unexpected. Nonetheless, both stable and dynamic NUPs have been found to have a role in particular aspects of development and to underlie specific human pathologies. Some compelling examples include mouse Nup133, which was recently demonstrated to have a role in embryonic development of the neural lineage, such that Nup133-null neural progenitors failed to efficiently produce terminally differentiated neurons (Lupu et al. 2008), and a mutation in human Nup155, which leads to atrial fibrillation (AF), an inherited form of clinical arrhythmia that can lead to sudden cardiac death (Zhang et al. 2008). The Drosophila homolog of Nup155, Nup154, has also been shown to have a tissue-specific role, but here instead affecting gametogenesis in both sexes (Gigliotti et al. 1998; Grimaldi et al. 2007). Furthermore, a mutation in the zebrafish ELYS was described to affect normal development and proliferation of the retina and the intestine (Davuluri et al. 2008; de Jong-Curtain et al. 2008). Mutations in several plant NUPs have been reported to cause diverse developmental defects, which often appear comparatively mild and relatively specific (Meier and Brkljacic 2009). One such example is a mutant allele of a nuclear basket NUP, Tpr/NUA, which affects the flowering time, seed production, and leaf morphology of Arabidopsis thaliana (Xu et al. 2007).

Perhaps the best-studied examples of a NUP underlying a particular human disorder are the identified translocations of the Nup 98 gene, which result in fusions of the amino-terminal part of Nup98 to transcriptional regulators and other DNA-binding proteins and have been characterized as mutations leading to several types of leukemia (Nakamura et al. 1996; Saito et al. 2004; Slape and Aplan 2004). For instance, the oncogenic fusion of Nup98 to the transcription factor HOXA9 results in acute myelogenous leukemia and was shown to induce the aberrant expression of HOXA9 target genes, beyond the effects of overexpression of HOXA9 alone, and to block the differentiation of human hematopoietic cells (Ghannam et al. 2004; Takeda et al. 2006). Fusions of Nup98 to PHD finger proteins have been shown to produce very similar effects and to lock target genes into an aberrantly active state, resulting in leukemic transformation (Wang et al. 2009). These findings agree with the notion that the normal function of Nup98 may include regulation of gene expression via direct interaction with target genes. Clearly, tissue-specific effects of the NPC can arise from its classic transport-associated or its recently identified chromatin-binding functions, or from the interplay of both. But to fully understand the mystery of how tissue-specific gene expression can be influenced by a particular NPC component, the chromatinassociated roles of NUPs have to be considered.

Originally, a relationship between nuclear pores and nuclear organization of chromatin was suggested by highresolution images of mammalian nuclei that distinctly show the nonrandom association of decondensed chromatin with nuclear pores. Such lighter-stained, decondensed chromatin is thought to contain predominantly active genes or parts of the genome that are more open and permissive to transcription. The observed correlation between NPCs and open chromatin led to a notion, known as the "gene-gating hypothesis" (Blobel 1985), which proposed that nuclear pores are capable of specifically interacting with active genes to promote coregulation of transcription with mRNA export. Several lines of evidence, subsequently obtained in yeast, supported this link of NPC to transcriptional activation. Genome-wide chromatin immunoprecipitation (ChIP) analysis in Saccharomyces cerevisiae showed that some nucleoporins, such as Mlp1, Nup2, and Nup60, often occupy regions of highly transcribed genes (Casolari et al. 2004, 2005). Furthermore, interaction between the NPC component Nup2 and promoters of active genes, termed the "NUP-PI" phenomenon, has been described (Schmid et al. 2006). Additionally, enhancing association of an inducible gene with the NPC boosted its transcript levels (Taddei et al. 2006), and genes reported to associate with NUPs were observed to relocalize to the nuclear periphery following transcriptional activation (Casolari et al. 2004; Taddei et al. 2006). These findings suggested that sites of active transcription are localized to the nuclear pores at the NE and appear to be positively regulated by the association with NUPs.

Interestingly, functional involvement of NUPs in gene activation has recently been discovered in multicellular organisms (Capelson et al. 2010; Kalverda et al. 2010; Vaquerizas et al. 2010), but with an unexpected twist. Analysis of chromatin-binding behavior of Drosophila NUPs, achieved by different methods such as immunostaining of polytene chromosomes, ChIP, and Dam-ID, revealed the presence of several NPC components at active genes and a functional requirement for their presence in transcription of their binding targets. Reducing levels of Nup98 or Sec13 by RNA interference (RNAi) resulted in decreased levels of transcriptional activity and mRNA levels of its target genes, which included the developmentally induced ecdysone-responsive genes (Capelson et al. 2010; 
Kalverda et al. 2010). Surprisingly, the NUP-chromatin contacts were commonly found to occur in the nucleoplasm, away from the NE-embedded NPCs. These observations, consistently reported by all three studies, suggest that NUPs may retain the ability to regulate gene activity even when not associated with the actual nuclear pore. The NUPs identified to participate in gene binding and regulation-namely, Nup98, Sec13, Nup62 - and other FG NUPs - Nup50, Nup153, and Tpr-belong to the peripheral and commonly dynamic subgroup of NUPs, with the exception of Sec13, which nevertheless has been reported to have an intranuclear population (Enninga et al. 2003). As discussed above, certain subcomplexes of the NPC, such as the Nup107-160 complex, form the main structural scaffold of the NPC. The components of such complexes have been found to be predictably stable at the NE-embedded formed NPCs, with low turnover rates as judged from fluorescence recovery after photobleaching (FRAP) experiments with GFP-tagged NUPs (Rabut et al. 2004). In contrast, peripheral NUPs that are recruited later during pore assembly have been found to be highly dynamic, with high turnover rates detected in similar FRAP experiments (Rabut et al. 2004). An intriguing possibility is that the dynamic behavior of these NUPs underlies their role in transcriptional activation. Dynamic NUPs could come off the nuclear pore to interact with transcribing genes or with mRNA and associated machinery inside the nucleus - that is, not at NE contact sites - a notion supported by the reported transcription-dependent mobility of Nup153 and Nup98 (Griffis et al. 2004). Because the majority of active genes are located in the nuclear interior, this model could overcome a major limitation of the genegating hypothesis, which argues that active genes have to be repositioned to the nuclear pores at the NE to be regulated by the NPC components.

Furthermore, one of the studies reported an additionally interesting type of NUP-chromatin interaction (Vaquerizas et al. 2010). According to the genome-wide ChIP data, both Nup153 and Megator (Mtor), the Drosophila homolog of Tpr, appear to occupy unusually long stretches of DNA, sometimes hundreds of kilobases (Vaquerizas et al. 2010), instead of the discrete binding peaks usually observed for transcriptional regulators and determined for Drosophila Nup98 (Capelson et al. 2010). This distribution is intriguing because it implies a global structural function for Nup153 and Mtor, which may underlie a functional organization of active genomic areas. It is tempting to speculate that such long Mtor/Tpr and Nup153 chromatin-binding stretches, termed nuclear pore-associated regions (NARs), may be an extension of the previously described Tpr filaments, which extend from the nucleoplasmic face of the NPC into the nucleoplasm (Zimowska and Paddy 2002; Krull et al. 2004). In this case, these nuclear basket filaments may interact with the genome to assist genomic targeting of imported transcription factors or to fulfill the gene-gating role of coupling mRNA production and export, previously assigned to NEembedded NPCs. In support of the latter idea, experiments in yeast have suggested a role for the homologs of Tpr, Mlp1/2 in down-regulating transcription of target genes in response to an mRNA export defect (Vinciguerra et al. 2005), implicating Mlp $1 / 2$ in coordinating the two processes. In flies, however, although a potential correlation between Tpr/Nup153-defined NARs and gene activity was reported, it does not appear to be absolute (Vaquerizas et al. 2010). Another recent study of Drosophila dosage compensation showed that Nup153 and Mtor/Tpr copurify with the Dosage Compensation Complex and are necessary for the twofold hypertranscription of the male $\mathrm{X}$ (Mendjan et al. 2006), further implicating these two NUPs in the establishment of active chromatin. The interaction itself may be indicative of a physical link between transcriptional or epigenetic activators and NUPs of the nuclear basket, which has been previously suggested in yeast (Rodriguez-Navarro et al. 2004; Casolari et al. 2005; Menon et al. 2005), but its functional role remains debated (Grimaud and Becker 2009). It is thus also possible that Tpr/Mtor and Nup153 NARs occupy regions of permissible, but not necessarily ongoing, transcription or regions of alternative processes or that they primarily constitute a structural support to chromatin organization, reminiscent of the suggested function for the components of the biochemically defined nuclear matrix (Vlcek et al. 2001; Marshall 2002).

These reports were the first to show a potential functional role for chromatin-associated NUPs in animal cells, raising an exciting possibility that NUPs execute a previously unexplored function in developmental gene activity. And although multiple studies on chromatin-associated roles of NUPs in yeast and flies showed their link to active genes, other reports have identified an association with genomic regions of alternative chromatin states. In the high-resolution images of nuclei mentioned above, in which heterochromatin looks interspersed by nuclear pores, it seems similarly plausible that the NPC would have a role in setting up this organization by serving as a boundary between condensed and decondensed regions. Boundary elements are generally defined by their ability to prevent communication between active and silent chromatin, which they are thought to do by physically partitioning the chromatin fiber (Gerasimova et al. 1995; Burgess-Beusse et al. 2002). Interestingly, examples of this type of involvement have been reported for the NPC: Yeast Nup2, Nup60, and Prp20/RanGEF were identified in a screen for chromatin boundary activities that can prevent the spreading of repressing factors into neighboring genes (Ishii et al. 2002; Dilworth et al. 2005). Furthermore, the initial characterization of the genome-wide chromatin distribution of yeast NUPs revealed that certain NPC components, such as Nup145C (homolog of mammalian Nup96) and Nup84 (homolog of Nup107), both considered stable NUPs, did not preferentially localize to active genes but, instead, were enriched on "neutral" chromatin (Casolari et al. 2004). Interestingly, the apparent exclusion of heterochromatin from the regions below the NPCs, mentioned above, is disrupted by a knockdown of Tpr in poliovirus-infected mammalian cells, allowing heterochromatin to form all along the NE (Krull et al. 2010). These unexpected findings suggest a potentially important role for Tpr in delimiting heterochromatin boundaries and 
support the proposed function of NUPs in setting up global chromatin organization.

Intriguingly, the only characterization of a genome-wide binding pattern of a stable NUP performed to date in mammalian cells showed an enrichment for repressive heterochromatic histone marks (Brown et al. 2008). ChIP analysis of Nup93 in human HeLa cells showed that its binding sites correlate with regions of high trimethylation of H3K9, H4K20, and H3K27. And, although these results were obtained from a correlation among different cell types and thus should be interpreted with caution, they serve as further potential evidence for the association of nuclear pores with inactive chromatin regions. Moreover, genomewide mapping of the Drosophila NPC components by DamID, which compared a full-length and an exclusively nucleoplasmic, NPC-uncoupled version of Nup98 (that had its NPC-interaction domain deleted), identified enrichment for gene activity only in the NPC-uncoupled data set (Kalverda et al. 2010). Genes associated with the components of the NE-embedded NPCc appeared to be frequently inactive. These results correlate well with the observed genomic binding of the stable Nup93, which is predominantly present at the nuclear pores and not in the nucleoplasm (Brown et al. 2008), suggesting that at least in animal cells, the actual NPC may not preferentially bind active chromatin and that the association of NUPs with active genes may be often performed off-pore.

Multiple lines of evidence outlined above support the existence of physical contacts between NPC components and specific genomic loci, prompting the questions of what are the molecular roles and mechanisms of these interactions? Do they exist to couple mRNA production to its eventual exit through the nuclear pores or to connect the entry of developmental transcription factors to their target genes? Can they, alternatively, involve interaction with inactive genomic regions for the possible purposes of chromatin organization and partitioning expression domains? Several studies, discussed below, have delved into the molecular mechanism of these interactions, shedding light on potential interacting partners and on possible cellular consequences arising from these contacts. The three main emerging links include a role for NUPs in transcriptional initiation, in coregulation of mRNA processing and export, and in establishment of chromatin domains to maintain transcriptional memory.

As what is perhaps the strongest evidence for the genegating model, yeast Sus1, a member of the mRNA export complex that physically interacts with the NPC component Nup1, was shown to be part of the histone acetyltransferase complex SAGA that is directly linked to transcriptional activation (Rodriguez-Navarro et al. 2004; Luthra et al. 2007). Histone acetylation is thought to have a role in setting up a transcriptionally permissive chromatin state, is enriched at gene promoters, and is associated with induction of transcription (MacDonald and Howe 2009). In addition, the recruitment of active GAL genes to the nuclear periphery and presumably to the NEembedded nuclear pores was shown to depend on Sus1 and other SAGA components (Cabal et al. 2006; Luthra et al. 2007). This interaction has recently been shown to be conserved, as E(y)2, the Drosophila homolog of a subunit of the SAGA complex, appears to anchor the heatshock protein 70 (hsp70) gene to the NPC and to be required for its efficient transcription (Kurshakova et al. 2007). Furthermore, mammalian Nup98 has been reported to interact physically with another histone acetyltransferase, CBP/p300 (Kasper et al. 1999). This interaction appears to be highly relevant to the cancer-associated roles of Nup98 because an oncogenic fusion of Nup98 to NSD1 histone methyltransferase was shown to produce aberrant activation, hyperacetylation, and recruitment of p300 to Hox-A genes in leukemogenesis (Wang et al. 2007). Moreover, when analyzed in developing salivary glands, Drosophila Nup98 and Sec13 were found to be recruited early on to their target genes, often preceding or coinciding with the first appearance of phosphorylated RNA polymerase II (RNAP II) (Capelson et al. 2010). This role in transcriptional induction agrees well with the report of interaction between NUPs and gene promoters during the early steps of transcriptional initiation in yeast, which proposed that transient contact with NPC proteins may be a general feature of gene activation (Schmid et al. 2006).

Recently, two new interesting candidates have been implicated in the association between transcribing genes and NPCs: (1) Some components of the exosome appear to mediate posttranscriptional tethering of GAL genes to the NPC (Vodala et al. 2008) and (2) the THO complex seems to link 3 '-end RNA processing to nuclear pore association (Rougemaille et al. 2008). Interestingly, during development, it appears that Drosophila FG NUPs are recruited to their target genes subsequent to recruitment of Nup98 and Sec13 and after the appearance of active RNAP II. Consistently, unlike Nup98 and Sec13, binding of FG NUPs to chromatin was found to be sensitive to treatment with Flavopiridol (Capelson et al. 2010), an inhibitor of the kinase Positive Transcription Elongation Factor b (P$\mathrm{TEFb}$ ) that specifically phosphorylates serine 2 of RNAP II CTD (Chao and Price 2001). Serine 2 phosphorylation has been proposed to be required for transition into efficient transcriptional elongation as well as be necessary for recruitment of mRNA processing factors (Cho et al. 2001; Shim et al. 2002). It appears plausible that FG NUPs and likely other NUPs as well may have a role in elongation and the mRNA processing that accompanies it.

Interestingly, sites of NPC residence on chromatin in yeast, identified by the ChIP approach (Casolari et al. 2004), and THO complex binding (Rougemaille et al. 2008) were preferentially located in the $3^{\prime}$ ends of active genes, unlike the promoter and $5^{\prime}$ region association observed in the NUP-PI phenomenon, which was discovered by mapping of the MNase-Nup2 fusion. One explanation for this apparent contradiction is the presence of both gene ends at the NPC through interactions with different NUPs, which would result in DNA looping. Such chromatin looping at the NPC has been recently directly observed for a particular subset of genes and appears to have a role in "remembering" recent transcriptional activity and thus in rapid reactivation of inducible loci (Brickner et al. 2007; Tan-Wong et al. 2009). The idea of the NPC being involved in chromatin domain establishment (or gene loop- 
ing) is further supported by the reports of certain yeast NUPs exhibiting boundary activity, mentioned above (Ishii et al. 2002).

As described above, during mitosis in higher eukaryotes, the NE and the nuclear pores break down and reform around newly segregated chromatin (Hetzer et al. 2005). Mitotic propagation of cell-specific chromatin architecture is intimately linked to this reassembly, yet how postmitotic nuclear reformation around chromatin translates into interphase chromatin organization is almost completely unknown. As discussed in the previous section, studies in Xenopus cell-free systems showed that a subcomplex of the NPC, the Nup107-160 complex, as well as ELYS, Nup153, and Nup358, are recruited to chromatin early in the postmitotic reassembly (Walther et al. $2003 \mathrm{a}, \mathrm{b})$. Thus, binding of a subset of NUPs to chromatin represents one of the initial events in nuclear reorganization, implicating metazoan nucleoporins as potential regulators of interphase chromatin architecture and, thus, of epigenetic memory. This suggested role in epigenetic memory supports the studies in yeast, where the long-term association of an inducible gene with the nuclear pore was reported to occur for several cell generations after the initial activation in yeast (Brickner et al. 2007). And, although yeast undergo closed mitosis and do not need to reform their NE, a role of the NPC in positional or epigenetic memory remains an intriguing possibility.

A possible model to integrate the diverse findings presented above could involve several distinct types of mechanisms by which the NPC regulates gene expression in a chromatin-associated manner (Fig. 3). One is the physical association of the stable NE-embedded nuclear pore structure with chromatin, which could have a role in tethering a chromatin boundary or in the general establishment of the three-dimensional (3D) organization of chromatin inside the nucleus. Because the stable core of the NPC does not turn over during the entire life span of a cell (D'Angelo et al. 2009), this extreme stability makes the core components of the NPC ideal candidates for establishing long-term transcription programs. The highly stable NPC core may serve as a scaffold for nuclear architecture of chromatin and could be used as a basis for epigenetic memory in differentiated cells. It appears that although some genes in yeast and metazoa contact the NE-embedded nuclear pores for activation, at least the metazoan NPC does not preferentially or exclusively bind transcribing genes and may bind other genomic regions for purely organizational purposes.

An alternative and additional mechanism would involve the binding of intranuclear NUPs to active genes, irrespective of the nuclear position of the genes. It remains to be determined whether intranuclear chromatin-binding NUPs shuttle between genomic sites and the nuclear periphery, which would be consistent with the dynamic behavior of some NUPs (Rabut et al. 2004). It is tempting to speculate that the mobility of NPC components may establish a mechanism of communication between sites of production of mRNA and sites of its final exit, similarly to what has been originally proposed for the NPC-chromatin relationship (Blobel 1985). In yeast, the intranuclear NUP-gene contacts have not been reported, and active genes have been observed to reposition to the membrane-associated
Active gene at pore

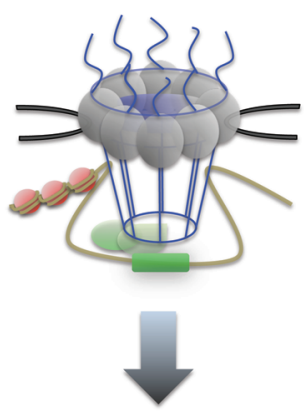

"Remembered"
through
cell divisions
Nonactive region at pore

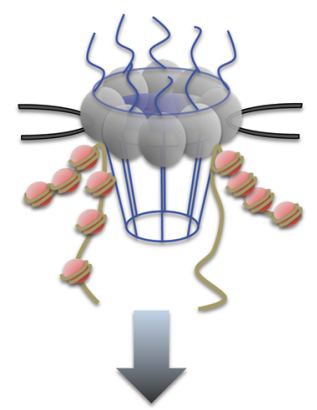

"Remembered through cell divisions?
Active gene off-pore

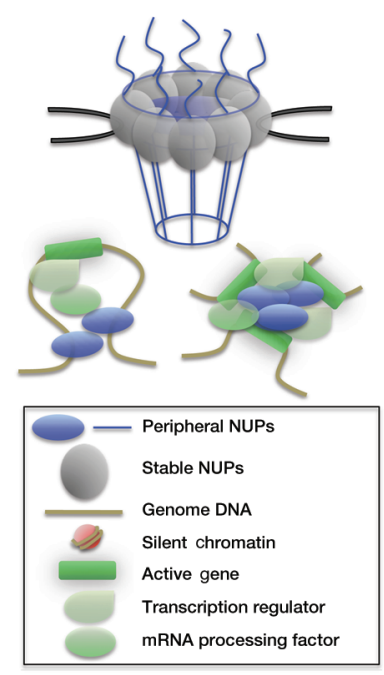

Figure 3. Schematic representation of three alternative hypotheses for the functional roles of genome-NPC contacts. As shown in yeast, NE-embedded NPCs may bind active genes at opposing ends, forming gene loops, to establish assembled transcription and processing domains that are "remembered" through cell divisions. Alternatively, and as may be more prevalent in metazoa, NE-associated NPCs may interact with boundary or nontranscribing genomic regions to similarly set up gene-expression domains or general nuclear chromatin organization. An intriguing possibility would be the use of such contacts for "remembering" a particular chromatin organization in differentiating or differentiated cells, the latter of which do not turn over their NPCs and remain stable for long periods of time. Finally, NE-independent NPC components may bind active genes in the nucleoplasm for the similar purposes of setting up local transcription and processing organization, which may involve gene looping or even gene contacts among distant loci. 
nuclear pores in several instances. It is thus unclear whether yeast only uses one mode for the chromatin-associated function of NUPs, which involves transcriptionally active genes being recruited to the NE-embedded NPCs. It is possible that intranuclear chromatin binding of NUPs has evolved preferentially in higher eukaryotes to compensate for larger nuclear size or for greater complexity of gene regulation. In Drosophila and possibly mammals, intranuclear NUPs may have retained the ability to interact with the transcription initiation apparatus and the mRNA processing machinery, and perhaps with both gene ends. In this manner, their role at genes undergoing induction may be to create an expression domain and set up a coregulation of the start and finish events of the transcription process. The long unstructured GLFG domain of Nup98 and FG repeats of FG NUPs may be perfect for this role as a scaffolding platform for mRNA production. In support of this hypothesis, leukemic fusions of Nup98 have been recently shown to self-interact with endogenous Nup98 in the intranuclear compartment (Xu and Powers 2010). It is possible to envision that the selfinteractions of Nup98 may even drive the clustering of distant gene loci onto a transcription platform, similarly to the model of transcription factories (Osborne et al. 2004; Mitchell and Fraser 2008). These diverse functional links lend to an intriguing model of the NPC as a potential nexus of key nuclear processes, integrating chromatin organization, transcription, and transport (Kohler and Hurt 2010). Assembly of transcription machinery and distant gene loci, mRNA processing, and export process, and, finally, the memory of these activating or chromatin-tethering events through cell divisions may all be in some ways connected to the NPC.

\section{ACKNOWLEDGMENTS}

We thank members of the Hetzer laboratory for excellent assistance and helpful comments. M.C. was supported by a Damon Runyon fellowship (DRG 1952-07). C.D. and M.H. are supported by grants from the National Institutes of Health (RO1GM057438) and the American Cancer Society RSG 09-178-01-DDC.

\section{REFERENCES}

Akhtar A, Gasser SM. 2007. The nuclear envelope and transcriptional control. Nat Rev Genet 8: 507-517.

Alber F, Dokudovskaya S, Veenhoff LM, Zhang W, Kipper J, Devos D, Suprapto A, Karni-Schmidt O, Williams R, Chait BT, et al. 2007. The molecular architecture of the nuclear pore complex. Nature 450: 695-701.

Anderson DJ, Hetzer MW. 2007. Nuclear envelope formation by chromatin-mediated reorganization of the endoplasmic reticulum. Nat Cell Biol 9: 1160-1166.

Anderson DJ, Hetzer MW. 2008a. Reshaping of the endoplasmic reticulum limits the rate for nuclear envelope formation. $J$ Cell Biol 182: 911-924.

Anderson DJ, Hetzer MW. 2008b. The life cycle of the metazoan nuclear envelope. Curr Opin Cell Biol 20: 386-392.

Anderson DJ, Vargas JD, Hsiao JP, Hetzer MW. 2009. Recruitment of functionally distinct membrane proteins to chromatin mediates nuclear envelope formation in vivo. J Cell Biol 186: 183191.

Antonin W, Franz C, Haselmann U, Antony C, Mattaj IW. 2005.
The integral membrane nucleoporin pom 121 functionally links nuclear pore complex assembly and nuclear envelope formation. Mol Cell 17: 83-92.

Antonin W, Ellenberg J, Dultz E. 2008. Nuclear pore complex assembly through the cell cycle: Regulation and membrane organization. FEBS Lett 582: 2004-2016.

Antonny B. 2006. Membrane deformation by protein coats. Curr Opin Cell Biol 18: 386-394.

Beck M, Forster F, Ecke M, Plitzko JM, Melchior F, Gerisch G, Baumeister W, Medalia O. 2004. Nuclear pore complex structure and dynamics revealed by cryoelectron tomography. Science 306: 1387-1390.

Blobel G. 1985. Gene gating: A hypothesis. Proc Natl Acad Sci 82: 8527-8529.

Bodoor K, Shaikh S, Salina D, Raharjo WH, Bastos R, Lohka M, Burke B. 1999. Sequential recruitment of NPC proteins to the nuclear periphery at the end of mitosis. J Cell Sci 112: 22532264.

Boehmer T, Enninga J, Dales S, Blobel G, Zhong H. 2003. Depletion of a single nucleoporin, Nup107, prevents the assembly of a subset of nucleoporins into the nuclear pore complex. Proc Natl Acad Sci 100: 981-985.

Brickner DG, Cajigas I, Fondufe-Mittendorf Y, Ahmed S, Lee PC, Widom J, Brickner JH. 2007. H2A.Z-mediated localization of genes at the nuclear periphery confers epigenetic memory of previous transcriptional state. PLoS Biol 5: e81. doi: 10.1371/ journal.pbio.0050081.

Brohawn SG, Schwartz TU. 2009. A lattice model of the nuclear pore complex. Commun Integr Biol 2: 205-207.

Brown CR, Silver PA. 2007. Transcriptional regulation at the nuclear pore complex. Curr Opin Genet Dev 17: 100-106.

Brown CR, Kennedy CJ, Delmar VA, Forbes DJ, Silver PA. 2008. Global histone acetylation induces functional genomic reorganization at mammalian nuclear pore complexes. Genes Dev 22: $627-639$.

Burgess-Beusse B, Farrell C, Gaszner M, Litt M, Mutskov V, Recillas-Targa F, Simpson M, West A, Felsenfeld G. 2002. The insulation of genes from external enhancers and silencing chromatin. Proc Natl Acad Sci (suppl. 4) 99: 16433-16437.

Burke B, Ellenberg J. 2002. Remodelling the walls of the nucleus. Nat Rev Mol Cell Biol 3: 486-497.

Cabal GG, Genovesio A, Rodriguez-Navarro S, Zimmer C, Gadal O, Lesne A, Buc H, Feuerbach-Fournier F, Olivo-Marin JC, Hurt EC, et al. 2006. SAGA interacting factors confine sub-diffusion of transcribed genes to the nuclear envelope. Nature 441: 770773.

Capelson M, Hetzer MW. 2009. The role of nuclear pores in gene regulation, development and disease. EMBO Rep 10: 697-705.

Capelson M, Liang Y, Schulte R, Mair W, Wagner U, Hetzer MW. 2010. Chromatin-bound nuclear pore components regulate gene expression in higher eukaryotes. Cell 140: 372-383.

Casolari JM, Brown CR, Komili S, West J, Hieronymus H, Silver PA. 2004. Genome-wide localization of the nuclear transport machinery couples transcriptional status and nuclear organization. Cell 117: 427-439.

Casolari JM, Brown CR, Drubin DA, Rando OJ, Silver PA. 2005. Developmentally induced changes in transcriptional program alter spatial organization across chromosomes. Genes Dev 19: 1188-1198.

Chadrin A, Hess B, San Roman M, Gatti X, Lombard B, Loew D, Barral Y, Palancade B, Doye V. 2010. Pom33, a novel transmembrane nucleoporin required for proper nuclear pore complex distribution. J Cell Biol 189: 795-811.

Chao SH, Price DH. 2001. Flavopiridol inactivates P-TEFb and blocks most RNA polymerase II transcription in vivo. J Biol Chem 276: 31793-31799.

Cho EJ, Kobor MS, Kim M, Greenblatt J, Buratowski S. 2001. Opposing effects of Ctk1 kinase and Fcp 1 phosphatase at Ser 2 of the RNA polymerase II C-terminal domain. Genes Dev 15: 3319-3329.

Dabauvalle MC, Scheer U. 1991. Assembly of nuclear pore complexes in Xenopus egg extract. Biol Cell 72: 25-29.

D'Angelo MA, Anderson DJ, Richard E, Hetzer MW. 2006. Nu- 
clear pores form de novo from both sides of the nuclear envelope. Science 312: 440-443.

D’Angelo MA, Raices M, Panowski SH, Hetzer MW. 2009. Agedependent deterioration of nuclear pore complexes causes a loss of nuclear integrity in postmitotic cells. Cell 136: 284-295.

Davuluri G, Gong W, Yusuff S, Lorent K, Muthumani M, Dolan AC, Pack M. 2008. Mutation of the zebrafish nucleoporin elys sensitizes tissue progenitors to replication stress. PLoS Genet 4: e1000240. doi: 10.1371/journal.pgen.1000240.

Dawson TR, Lazarus MD, Hetzer MW, Wente SR. 2009. ER membrane-bending proteins are necessary for de novo nuclear pore formation. J Cell Biol 184: 659-675.

Debler EW, Ma Y, Seo HS, Hsia KC, Noriega TR, Blobel G, Hoelz A. 2008. A fence-like coat for the nuclear pore membrane. Mol Cell 32: 815-826.

De Craene JO, Coleman J, Estrada de Martin P, Pypaert M, Anderson S, Yates JR III, Ferro-Novick S, Novick P. 2006. Rtn1p is involved in structuring the cortical endoplasmic reticulum. Mol Biol Cell 17: 3009-3020.

de Jong-Curtain TA, Parslow AC, Trotter AJ, Hall NE, Verkade H, Tabone T, Christie EL, Crowhurst MO, Layton JE, Shepherd IT, et al. 2008. Abnormal nuclear pore formation triggers apoptosis in the intestinal epithelium of elys-deficient zebrafish. Gastroenterology 136: 902-911.

Dilworth DJ, Tackett AJ, Rogers RS, Yi EC, Christmas RH, Smith JJ, Siegel AF, Chait BT, Wozniak RW, Aitchison JD. 2005. The mobile nucleoporin Nup2p and chromatin-bound Prp20p function in endogenous NPC-mediated transcriptional control. J Cell Biol 171: 955-965.

Doucet CM, Talamas JA, Hetzer MW. 2010. Cell cycle-dependent differences in nuclear pore complex assembly in metazoa. Cell 141: 1030-1041.

Drin G, Casella JF, Gautier R, Boehmer T, Schwartz TU, Antonny B. 2007. A general amphipathic $\alpha$-helical motif for sensing membrane curvature. Nat Struct Mol Biol 14: 138-146.

Dultz E, Ellenberg J. 2010. Live imaging of single nuclear pores reveals unique assembly kinetics and mechanism in interphase. J Cell Biol 191: 15-22.

Dultz E, Zanin E, Wurzenberger C, Braun M, Rabut G, Sironi L, Ellenberg J. 2008. Systematic kinetic analysis of mitotic disand reassembly of the nuclear pore in living cells. J Cell Biol 180: $857-865$.

Enninga J, Levay A, Fontoura BM. 2003. Sec13 shuttles between the nucleus and the cytoplasm and stably interacts with Nup96 at the nuclear pore complex. Mol Cell Biol 23: 7271-7284.

Fichtman B, Ramos C, Rasala B, Harel A, Forbes DJ. 2010. Inner/ outer nuclear membrane fusion in nuclear pore assembly: Biochemical demonstration and molecular analysis. Mol Biol Cell 21: 4197-4211.

Flemming D, Sarges P, Stelter P, Hellwig A, Bottcher B, Hurt E. 2009. Two structurally distinct domains of the nucleoporin Nup170 cooperate to tether a subset of nucleoporins to nuclear pores. J Cell Biol 185: 387-395.

Forbes DJ. 1992. Structure and function of the nuclear pore complex. Annu Rev Cell Biol 8: 495-527.

Franz C, Askjaer P, Antonin W, Iglesias CL, Haselmann U, Schelder M, de Marco A, Wilm M, Antony C, Mattaj IW. 2005. Nup155 regulates nuclear envelope and nuclear pore complex formation in nematodes and vertebrates. EMBO J 24: 35193531 .

Franz C, Walczak R, Yavuz S, Santarella R, Gentzel M, Askjaer P, Galy V, Hetzer M, Mattaj IW, Antonin W. 2007. MEL-28/ELYS is required for the recruitment of nucleoporins to chromatin and postmitotic nuclear pore complex assembly. EMBO Rep 8: 165172.

Frey S, Gorlich D. 2007. A saturated FG-repeat hydrogel can reproduce the permeability properties of nuclear pore complexes. Cell 130: 512-523.

Galy V, Mattaj IW, Askjaer P. 2003. Caenorhabditis elegans nucleoporins Nup93 and Nup205 determine the limit of nuclear pore complex size exclusion in vivo. Mol Biol Cell 14: 5104 5115.

Galy V, Antonin W, Jaedicke A, Sachse M, Santarella R, Hasel- mann U, Mattaj I. 2008. A role for gp210 in mitotic nuclear-envelope breakdown. J Cell Sci 121: 317-328.

Gerasimova TI, Gdula DA, Gerasimov DV, Simonova O, Corces VG. 1995. A Drosophila protein that imparts directionality on a chromatin insulator is an enhancer of position-effect variegation. Cell 82: 587-597.

Ghannam G, Takeda A, Camarata T, Moore MA, Viale A, Yaseen NR. 2004. The oncogene Nup98-HOXA9 induces gene transcription in myeloid cells. J Biol Chem 279: 866-875.

Gigliotti S, Callaini G, Andone S, Riparbelli MG, Pernas-Alonso R, Hoffmann G, Graziani F, Malva C. 1998. Nup154, a new Drosophila gene essential for male and female gametogenesis is related to the nup 155 vertebrate nucleoporin gene. J Cell Biol 142: $1195-1207$.

Goldberg MW, Wiese C, Allen TD, Wilson KL. 1997. Dimples, pores, star-rings, and thin rings on growing nuclear envelopes: Evidence for structural intermediates in nuclear pore complex assembly. J Cell Sci 110: 409-420.

Griffis ER, Craige B, Dimaano C, Ullman KS, Powers MA. 2004. Distinct functional domains within nucleoporins Nup153 and Nup98 mediate transcription-dependent mobility. Mol Biol Cell 15: 1991-2002.

Grimaldi MR, Cozzolino L, Malva C, Graziani F, Gigliotti S. 2007. nup 154 genetically interacts with cup and plays a cell-type-specific function during Drosophila melanogaster egg-chamber development. Genetics 175: 1751-1759.

Grimaud C, Becker PB. 2009. The dosage compensation complex shapes the conformation of the X chromosome in Drosophila. Genes Dev 23: 2490-2495.

Haraguchi T, Koujin T, Hayakawa T, Kaneda T, Tsutsumi C, Imamoto N, Akazawa C, Sukegawa J, Yoneda Y, Hiraoka Y. 2000. Live fluorescence imaging reveals early recruitment of emerin, LBR, RanBP2, and Nup153 to reforming functional nuclear envelopes. J Cell Sci 113: 779-794.

Harel A, Chan RC, Lachish-Zalait A, Zimmerman E, Elbaum M, Forbes DJ. 2003a. Importin $\beta$ negatively regulates nuclear membrane fusion and nuclear pore complex assembly. Mol Biol Cell 14: $4387-4396$.

Harel A, Orjalo AV, Vincent T, Lachish-Zalait A, Vasu S, Shah S, Zimmerman E, Elbaum M, Forbes DJ. 2003b. Removal of a single pore subcomplex results in vertebrate nuclei devoid of nuclear pores. Mol Cell 11: 853-864.

Hase ME, Cordes VC. 2003. Direct interaction with nup153 mediates binding of Tpr to the periphery of the nuclear pore complex. Mol Biol Cell 14: 1923-1940.

Hawryluk-Gara LA, Shibuya EK, Wozniak RW. 2005. Vertebrate Nup53 interacts with the nuclear lamina and is required for the assembly of a Nup93-containing complex. Mol Biol Cell 16: 2382-2394.

Hetzer M, Walther TC, Mattaj IW. 2005. Pushing the envelope: Structure, function, and dynamics of the nuclear periphery. Annu Rev Cell Dev Biol. 21: 347-380.

Hinshaw JE, Carragher BO, Milligan RA. 1992. Architecture and design of the nuclear pore complex. Cell 69: 1133-1141.

Ishii K, Arib G, Lin C, Van Houwe G, Laemmli UK. 2002. Chromatin boundaries in budding yeast: The nuclear pore connection. Cell 109: 551-562.

Jovanovic-Talisman T, Tetenbaum-Novatt J, McKenney AS, Zilman A, Peters R, Rout MP, Chait BT. 2009. Artificial nanopores that mimic the transport selectivity of the nuclear pore complex. Nature 457: 1023-1027.

Kalverda B, Pickersgill H, Shloma VV, Fornerod M. 2010. Nucleoporins directly stimulate expression of developmental and cellcycle genes inside the nucleoplasm. Cell 140: 360-371.

Kasper LH, Brindle PK, Schnabel CA, Pritchard CE, Cleary ML, van Deursen JM. 1999. CREB binding protein interacts with nucleoporin-specific FG repeats that activate transcription and mediate NUP98-HOXA9 oncogenicity. Mol Cell Biol 19: 764 776.

Katsani KR, Karess RE, Dostatni N, Doye V. 2008. In vivo dynamics of Drosophila nuclear envelope components. Mol Biol Cell 19: 3652-3666.

Kohler A, Hurt E. 2007. Exporting RNA from the nucleus to the 
cytoplasm. Nat Rev Mol Cell Biol 8: 761-773.

Kohler A, Hurt E. 2010. Gene regulation by nucleoporins and links to cancer. Mol Cell 38: 6-15.

Krull S, Thyberg J, Bjorkroth B, Rackwitz HR, Cordes VC. 2004. Nucleoporins as components of the nuclear pore complex core structure and tpr as the architectural element of the nuclear basket. Mol Biol Cell 15: 4261-4277.

Krull S, Dorries J, Boysen B, Reidenbach S, Magnius L, Norder H, Thyberg J, Cordes VC. 2010. Protein Tpr is required for establishing nuclear pore-associated zones of heterochromatin exclusion. EMBO J 29: 1659-1673.

Kurshakova MM, Krasnov AN, Kopytova DV, Shidlovskii YV, Nikolenko JV, Nabirochkina EN, Spehner D, Schultz P, Tora L, Georgieva SG. 2007. SAGA and a novel Drosophila export complex anchor efficient transcription and mRNA export to NPC. EMBO J 26: 4956-4965.

Lim RY, Ullman KS, Fahrenkrog B. 2008. Biology and biophysics of the nuclear pore complex and its components. Int Rev Cell Mol Biol 267: 299-342.

Liu HL, De Souza CP, Osmani AH, Osmani SA. 2009. The three fungal transmembrane nuclear pore complex proteins of $A s-$ pergillus nidulans are dispensable in the presence of an intact An-Nup84-120 complex. Mol Biol Cell 20: 616-630.

Lupu F, Alves A, Anderson K, Doye V, Lacy E. 2008. Nuclear pore composition regulates neural stem/progenitor cell differentiation in the mouse embryo. Dev Cell 14: 831-842.

Lusk CP, Makhnevych T, Marelli M, Aitchison JD, Wozniak RW. 2002. Karyopherins in nuclear pore biogenesis: A role for Kap $121 \mathrm{p}$ in the assembly of Nup53p into nuclear pore complexes. J Cell Biol 159: 267-278.

Luthra R, Kerr SC, Harreman MT, Apponi LH, Fasken MB, Ramineni S, Chaurasia S, Valentini SR, Corbett AH. 2007. Actively transcribed GAL genes can be physically linked to the nuclear pore by the SAGA chromatin modifying complex. J Biol Chem 282: 3042-3049.

MacDonald VE, Howe LJ. 2009. Histone acetylation: Where to go and how to get there. Epigenetics 4: 139-143.

Madrid AS, Mancuso J, Cande WZ, Weis K. 2006. The role of the integral membrane nucleoporins Ndc1p and Pom152p in nuclear pore complex assembly and function. J Cell Biol 173: 361-371.

Makio T, Stanton LH, Lin CC, Goldfarb DS, Weis K, Wozniak RW. 2009. The nucleoporins Nup170p and Nup157p are essential for nuclear pore complex assembly. J Cell Biol 185: 459-473.

Mansfeld J, Guttinger S, Hawryluk-Gara LA, Pante N, Mall M, Galy V, Haselmann U, Muhlhausser P, Wozniak RW, Mattaj IW, et al. 2006. The conserved transmembrane nucleoporin NDC1 is required for nuclear pore complex assembly in vertebrate cells. Mol Cell 22: 93-103.

Marelli M, Lusk CP, Chan H, Aitchison JD, Wozniak RW. 2001. A link between the synthesis of nucleoporins and the biogenesis of the nuclear envelope. J Cell Biol 153: 709-724.

Marshall WF. 2002. Order and disorder in the nucleus. Curr Biol 12: R185-R192.

Maul GG, Price JW, Lieberman MW. 1971. Formation and distribution of nuclear pore complexes in interphase. J Cell Biol 51: 405-418.

Meier I, Brkljacic J. 2009. The nuclear pore and plant development. Curr Opin Plant Biol 12: 87-95.

Mendjan S, Taipale M, Kind J, Holz H, Gebhardt P, Schelder M, Vermeulen M, Buscaino A, Duncan K, Mueller J, et al. 2006. Nuclear pore components are involved in the transcriptional regulation of dosage compensation in Drosophila. Mol Cell 21: 811-823.

Menon BB, Sarma NJ, Pasula S, Deminoff SJ, Willis KA, Barbara KE, Andrews B, Santangelo GM. 2005. Reverse recruitment: The Nup84 nuclear pore subcomplex mediates Rap1/Gcr1/Gcr2 transcriptional activation. Proc Natl Acad Sci 102: 5749-5754.

Miao M, Ryan KJ, Wente SR. 2006. The integral membrane protein Pom $34 \mathrm{p}$ functionally links nucleoporin subcomplexes. Genetics 172: 1441-1457.

Mitchell JA, Fraser P. 2008. Transcription factories are nuclear subcompartments that remain in the absence of transcription. Genes
Dev 22: 20-25.

Nakamura T, Largaespada DA, Lee MP, Johnson LA, Ohyashiki K, Toyama K, Chen SJ, Willman CL, Chen IM, Feinberg AP, et al. 1996. Fusion of the nucleoporin gene NUP98 to HOXA9 by the chromosome translocation $\mathrm{t}(7 ; 11)(\mathrm{p} 15 ; \mathrm{p} 15)$ in human myeloid leukaemia. Nat Genet 12: 154-158.

Oertle T, Schwab ME. 2003. Nogo and its paRTNers. Trends Cell Biol 13: 187-194.

Olsson M, Schéele S, Ekblom P. 2004. Limited expression of nuclear pore membrane glycoprotein 210 in cell lines and tissues suggests cell-type specific nuclear pores in metazoans. Exp Cell Res 292: 359-370.

Onischenko E, Stanton LH, Madrid AS, Kieselbach T, Weis K. 2009. Role of the Ndc1 interaction network in yeast nuclear pore complex assembly and maintenance. J Cell Biol 185: 475491.

Osborne CS, Chakalova L, Brown KE, Carter D, Horton A, Debrand E, Goyenechea B, Mitchell JA, Lopes S, Reik W, et al. 2004. Active genes dynamically colocalize to shared sites of ongoing transcription. Nat Genet 36: 1065-1071.

Patel SS, Rexach MF. 2008. Discovering novel interactions at the nuclear pore complex using bead halo: A rapid method for detecting molecular interactions of high and low affinity at equilibrium. Mol Cell Proteomics 7: 121-131.

Rabut G, Doye V, Ellenberg J. 2004. Mapping the dynamic organization of the nuclear pore complex inside single living cells. Nat Cell Biol 6: 1114-1121.

Rasala BA, Orjalo AV, Shen Z, Briggs S, Forbes DJ. 2006. ELYS is a dual nucleoporin/kinetochore protein required for nuclear pore assembly and proper cell division. Proc Natl Acad Sci 103: 17801-17806.

Rasala BA, Ramos C, Harel A, Forbes DJ. 2008. Capture of ATrich chromatin by ELYS recruits POM121 and NDC1 to initiate nuclear pore assembly. Mol Biol Cell 19: 3982-3996.

Rodriguez-Navarro S, Fischer T, Luo MJ, Antunez O, Brettschneider S, Lechner J, Perez-Ortin JE, Reed R, Hurt E. 2004. Sus1, a functional component of the SAGA histone acetylase complex and the nuclear pore-associated mRNA export machinery. Cell 116: $75-86$.

Rotem A, Gruber R, Shorer H, Shaulov L, Klein E, Harel A. 2009. Importin $\beta$ regulates the seeding of chromatin with initiation sites for nuclear pore assembly. Mol Biol Cell 20: 4031-4042.

Rougemaille M, Dieppois G, Kisseleva-Romanova E, Gudipati RK, Lemoine S, Blugeon C, Boulay J, Jensen TH, Stutz F, Devaux F, et al. 2008. THO/Sub2p functions to coordinate $3^{\prime}$-end processing with gene-nuclear pore association. Cell 135: 308321.

Ryan KJ, McCaffery JM, Wente SR. 2003. The Ran GTPase cycle is required for yeast nuclear pore complex assembly. J Cell Biol 160: 1041-1053.

Saito S, Miyaji-Yamaguchi M, Nagata K. 2004. Aberrant intracellular localization of SET-CAN fusion protein, associated with a leukemia, disorganizes nuclear export. Int J Cancer 111: 501507.

Schmid M, Arib G, Laemmli C, Nishikawa J, Durussel T, Laemmli UK. 2006. Nup-PI: The nucleopore-promoter interaction of genes in yeast. Mol Cell 21: 379-391.

Sheetz MP, Painter RG, Singer SJ. 1976. Biological membranes as bilayer couples. III. Compensatory shape changes induced in membranes. J Cell Biol 70: 193-203.

Shibata Y, Voss C, Rist JM, Hu J, Rapoport TA, Prinz WA, Voeltz GK. 2008. The reticulon and DP1/Yop1p proteins form immobile oligomers in the tubular endoplasmic reticulum. $J$ Biol Chem 283: 18892-18904.

Shim EY, Walker AK, Shi Y, Blackwell TK. 2002. CDK-9/cyclin $\mathrm{T}(\mathrm{P}-\mathrm{TEFb})$ is required in two postinitiation pathways for transcription in the C. elegans embryo. Genes Dev 16: 2135-2146.

Shulga N, Mosammaparast N, Wozniak R, Goldfarb DS. 2000. Yeast nucleoporins involved in passive nuclear envelope permeability. J Cell Biol 149: 1027-1038.

Siniossoglou S, Wimmer C, Rieger M, Doye V, Tekotte H, Weise C, Emig S, Segref A, Hurt EC. 1996. A novel complex of nucleoporins, which includes Sec13p and a Sec13p homolog, is 
essential for normal nuclear pores. Cell 84: 265-275.

Slape C, Aplan PD. 2004. The role of NUP98 gene fusions in hematologic malignancy. Leuk Lymphoma 45: 1341-1350.

Stavru F, Hulsmann BB, Spang A, Hartmann E, Cordes VC, Gorlich D. 2006a. NDC1: A crucial membrane-integral nucleoporin of metazoan nuclear pore complexes. J Cell Biol 173: 509-519.

Stavru F, Nautrup-Pedersen G, Cordes VC, Gorlich D. 2006b. Nuclear pore complex assembly and maintenance in POM121- and gp210-deficient cells. J Cell Biol 173: 477-483.

Stoffler D, Feja B, Fahrenkrog B, Walz J, Typke D, Aebi U. 2003. Cryo-electron tomography provides novel insights into nuclear pore architecture: Implications for nucleocytoplasmic transport. J Mol Biol 328: 119-130.

Strambio-De-Castillia C, Niepel M, Rout MP. 2010. The nuclear pore complex: Bridging nuclear transport and gene regulation. Nat Rev Mol Cell Biol 11: 490-501.

Taddei A, Van Houwe G, Hediger F, Kalck V, Cubizolles F, Schober H, Gasser SM. 2006. Nuclear pore association confers optimal expression levels for an inducible yeast gene. Nature 441: 774 778.

Takeda A, Goolsby C, Yaseen NR. 2006. NUP98-HOXA9 induces long-term proliferation and blocks differentiation of primary human CD34+ hematopoietic cells. Cancer Res 66: 6628-6637.

Tan-Wong SM, Wijayatilake HD, Proudfoot NJ. 2009. Gene loops function to maintain transcriptional memory through interaction with the nuclear pore complex. Genes Dev 23: 2610-2624.

Terry LJ, Wente SR. 2009. Flexible gates: Dynamic topologies and functions for FG nucleoporins in nucleocytoplasmic transport. Eukaryot Cell 8: 1814-1827.

Terry LJ, Shows EB, Wente SR. 2007. Crossing the nuclear envelope: Hierarchical regulation of nucleocytoplasmic transport. Science 318: 1412-1416.

Vaquerizas JM, Suyama R, Kind J, Miura K, Luscombe NM, Akhtar A. 2010. Nuclear pore proteins Nup153 and megator define transcriptionally active regions in the Drosophila genome. PLoS Genet 6: e1000846. doi: 10.1371/journal.pgen.1000846.

Vinciguerra P, Iglesias N, Camblong J, Zenklusen D, Stutz F. 2005. Perinuclear Mlp proteins downregulate gene expression in response to a defect in mRNA export. EMBO J 24: 813-823.

Vlcek S, Dechat T, Foisner R. 2001. Nuclear envelope and nuclear matrix: Interactions and dynamics. Cell Mol Life Sci 58: 17581765.

Vodala S, Abruzzi KC, Rosbash M. 2008. The nuclear exosome and adenylation regulate posttranscriptional tethering of yeast GAL genes to the nuclear periphery. Mol Cell 31: 104-113.

Voeltz GK, Prinz WA, Shibata Y, Rist JM, Rapoport TA. 2006. A class of membrane proteins shaping the tubular endoplasmic reticulum. Cell 124: 573-586.

Walde S, Kehlenbach RH. 2010. The part and the whole: Functions of nucleoporins in nucleocytoplasmic transport. Trends Cell Biol 20: 461-469.

Walther TC, Fornerod M, Pickersgill H, Goldberg M, Allen TD, Mattaj IW. 2001. The nucleoporin Nup153 is required for nu- clear pore basket formation, nuclear pore complex anchoring and import of a subset of nuclear proteins. EMBO J 20: 57035714.

Walther TC, Alves A, Pickersgill H, Loiodice I, Hetzer M, Galy V, Hulsmann BB, Kocher T, Wilm M, Allen T, et al. 2003a. The conserved Nup107-160 complex is critical for nuclear pore complex assembly. Cell 113: 195-206.

Walther TC, Askjaer P, Gentzel M, Habermann A, Griffiths G, Wilm M, Mattaj IW, Hetzer M. 2003b. RanGTP mediates nuclear pore complex assembly. Nature 424: 689-694.

Wang GG, Cai L, Pasillas MP, Kamps MP. 2007. NUP98-NSD1 links H3K36 methylation to Hox-A gene activation and leukaemogenesis. Nat Cell Biol 9: 804-812.

Wang GG, Song J, Wang Z, Dormann HL, Casadio F, Li H, Luo JL, Patel DJ, Allis CD. 2009. Haematopoietic malignancies caused by dysregulation of a chromatin-binding PHD finger. Nature 459: 847-851.

Weis K. 2003. Regulating access to the genome: Nucleocytoplasmic transport throughout the cell cycle. Cell 112: 441-451.

Whittle JR, Schwartz TU. 2009. Architectural nucleoporins Nup157/ 170 and Nup133 are structurally related and descend from a second ancestral element. J Biol Chem 284: 28442-28452.

Winey M, Yarar D, Giddings TH Jr, Mastronarde DN. 1997. Nuclear pore complex number and distribution throughout the $\mathrm{Sac}$ charomyces cerevisiae cell cycle by three-dimensional reconstruction from electron micrographs of nuclear envelopes. Mol Biol Cell 8: 2119-2132.

Wozniak R, Burke B, Doye V. 2010. Nuclear transport and the mitotic apparatus: An evolving relationship. Cell Mol Life Sci 67: 2215-2230.

Wu X, Kasper LH, Mantcheva RT, Mantchev GT, Springett MJ, van Deursen JM. 2001. Disruption of the FG nucleoporin NUP98 causes selective changes in nuclear pore complex stoichiometry and function. Proc Natl Acad Sci 98: 3191-3196.

Xu S, Powers MA. 2010. Nup98-homeodomain fusions interact with endogenous Nup98 during interphase and localize to kinetochores and chromosome arms during mitosis. Mol Biol Cell 21: $1585-1596$.

Xu XM, Rose A, Muthuswamy S, Jeong SY, Venkatakrishnan S, Zhao Q, Meier I. 2007. NUCLEAR PORE ANCHOR, the Arabidopsis homolog of Tpr/Mlp1/Mlp2/megator, is involved in mRNA export and SUMO homeostasis and affects diverse aspects of plant development. Plant Cell 19: 1537-1548.

Yavuz S, Santarella-Mellwig R, Koch B, Jaedicke A, Mattaj IW, Antonin W. 2010. NLS-mediated NPC functions of the nucleoporin Pom121. FEBS Lett 584: 3292-3298.

Zhang X, Chen S, Yoo S, Chakrabarti S, Zhang T, Ke T, Oberti C, Yong SL, Fang F, Li L, et al. 2008. Mutation in nuclear pore component NUP155 leads to atrial fibrillation and early sudden cardiac death. Cell 135: 1017-1027.

Zimowska G, Paddy MR. 2002. Structures and dynamics of Drosophila Tpr inconsistent with a static, filamentous structure. Exp Cell Res 276: 223-232. 


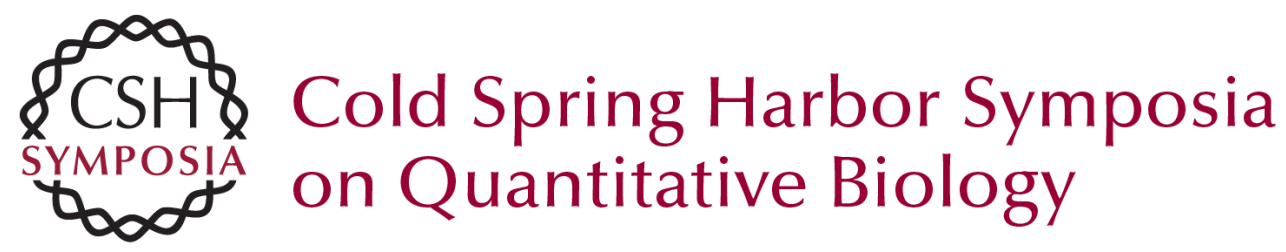

\section{Nuclear Pore Complexes: Guardians of the Nuclear Genome}

M. Capelson, C. Doucet and M.W. Hetzer

Cold Spring Harb Symp Quant Biol 2010 75: 585-597 originally published online April 18, 2011 Access the most recent version at doi:10.1101/sqb.2010.75.059

References This article cites 141 articles, 67 of which can be accessed free at: http://symposium.cshlp.org/content/75/585.full.htmI\#ref-list-1

\section{License}

Email Alerting Receive free email alerts when new articles cite this article - sign up in Service the box at the top right corner of the article or click here. 